\title{
Raça e criminalidade na obra de Nina Rodrigues: Uma história psicossocial dos estudos raciais no Brasil do final do século XIX
}

\section{Race and crime on Nina Rodrigues work: A psychosocial history of racial studies in Brazil from the late nineteenth century}

\section{La raza y la delincuencia en la obra de Nina Rodrigues: Una historia psicosocial de los estudios raciales en Brasil a finales del siglo $X I X$}

\section{Marcela Franzen Rodrigues*}

Universidade do Estado do Rio de Janeiro - UERJ, Rio de Janeiro, Rio de Janeiro, Brasil

\section{RESUMO}

Este artigo tem por intuito rever e analisar algumas obras de Nina Rodrigues (1862-1906) que tratam, sobretudo, de seus trabalhos acerca da inferioridade física e mental dos negros e mestiços no Brasil, baseando-se mormente no saber produzido por criminalistas italianos como Lombroso, Garófalo e Ferri. Raimundo Nina Rodrigues foi um médico maranhense, radicado na Bahia, que no final do século XIX interessou-se pelos estudos raciais a partir da Medicina Legal. Produziu diversas obras nas quais busca explicar e analisar o que ele considerava provas irrefutáveis da inferioridade da raça negra. Assim, Nina Rodrigues se debruçava sobre casos de crimes, de loucura, de crenças religiosas, sempre na busca de pistas que pudessem comprovar suas teorias sobre a inferioridade racial. Neste trabalho procurase analisar tais obras, a fim de apreender as motivações do autor assim como compreender o contexto científico da época, buscando-se, assim, alguma contribuição para a história da psicologia no Brasil.

Palavras-Chave: Nina Rodrigues, raça, crime, medicina legal, história da psicologia.

\footnotetext{
ABSTRACT

This article intends to review and analyze some works of Nina Rodrigues (1862-1906) what talk about physical and mental inferiority of black and mixed race people in Brazil, based mainly on the knowledge produced by I talian criminologists such as Lombroso, Garofalo and Ferri. Raimundo Nina Rodrigues was a medical from Maranhão, based in Bahia, which in the late nineteenth century was interested in the racial studies from the Forensic Medicine. He wrote several works in which he explains and analyzes what was considered irrefutable proof of the inferiority of the black race. So, Nina Rodrigues analyzed incidents of crime, madness, religious beliefs, always in search of clues that might prove his theories about racial inferiority. This
} 
paper analyzes these works a view to apprehend the motivations of the author as well as understand the scientific context of the time, trying to give some contribution to the field of history of psychology in Brazil.

Keywords: Nina Rodrigues, race, crime, forensic medicine, history of psychology.

\section{RESUMEN}

Este artículo tiene como objetivo revisar y analizar algunas obras de Nina Rodrigues (1862-1906) que hablan de su trabajo con los estudios de inferioridad física y mental entre los negros y mestizos en Brasil, basada principalmente en el conocimiento producido por los criminólogos italianos como Lombroso, Garofalo y Ferri. Raimundo Nina Rodrigues fue un médico nacido en Maranhão, pero arraigado en Bahía, que a finales del siglo XIX se interesó por los estudios raciales de la Medicina Forense. Él produjo varias obras en que trata de explicar y analizar lo que él consideraba una prueba irrefutable de la inferioridad de la raza negra. Así, Nina Rodrigues se apoyó en algunos casos de la delincuencia, de la locura, de las creencias religiosas, siempre en busca de indicios que afirmasen sus teorías de la inferioridad racial. Este artículo tiene por objeto examinar estas obras con el fin de entender las motivaciones del autor, así como entender el contexto científico de la época, tratando así de dar alguna contribución a la historia de la psicología en Brasil.

Palabras clave: Nina Rodrigues, raza, delito, medicina legal, historia de la psicología.

\section{I ntrodução}

Raimundo Nina Rodrigues foi um médico brasileiro que no final do século XIX buscou, entre outras coisas, desvendar os mistérios da mente e do espírito dos negros brasileiros. Racista, eugenista, conservador, foi um intelectual rejeitado a partir da segunda metade do século XX por conta destas características que, se não eram, à época, exclusivas dele, tornaram-se malditas: hoje em dia seu nome quase não é citado, a não ser em revisões críticas da história dos estudos raciais. Sua produção não foi muito extensa temporalmente cerca de vinte anos - mas foi intensa, no sentido de que escreveu muito sobre temas diversos, apesar de ter se mantido fiel aos chamados estudos do negro.

Nina Rodrigues nasceu em Vargem Grande, município do Maranhão, em 1862. Aos 20 anos de idade mudou-se para a Bahia, a fim de cursar a Faculdade de Medicina. Já com o título de doutor ${ }^{1}$, Nina Rodrigues, em 1888, foi para a cidade de São Luís do Maranhão, onde clinicou durante algum tempo, tendo, neste período escrito artigos sobre higiene pública e também um trabalho sobre a lepra, no qual se encontra a sua primeira tentativa de um quadro classificatório das raças no Maranhão. Em 1889 voltou para a Salvador a fim de assumir a Cadeira de Clínica Médica na Faculdade de Medicina da Bahia e no mesmo ano passou a fazer parte da redação da Gazeta Médica da Bahia, uma das mais importantes publicações médicas do 
País (Oda, 2003; Schwarcz, 1993). Em 1891, foi transferido para a disciplina de Medicina Legal, primeiramente como substituto, sendo oficializado no cargo quatro anos depois. Até sua morte, em 1906, Nina Rodrigues permaneceu neste cargo, desempenhando importante papel na institucionalização da Medicina Legal no país.

A produção de Nina Rodrigues foi ampla, abarcando diversas áreas da medicina - sendo mais efetiva na medicina legal, mas não restrita a ela. Entre os anos de 1890 e 1892, escreveu sobre as epidemias de abasia astasia ocorridas no Maranhão e na Bahia, além de textos voltados à discussão da mestiçagem, como "Mestiçagem, Degenerescência e Crime".

Publicou o seu primeiro livro - "As raças humanas e a responsabilidade penal no Brasil" - em 1894, hoje considerada uma de suas mais importantes obras. Este livro era, segundo o autor, um "estudo das modificações que as condições de raça imprimem à responsabilidade penal" (Rodrigues, 1957, p.27), com o objetivo de sistematizar as suas lições na disciplina de Medicina Legal (Oda, 2003).

Em 1895, já como titular na cátedra de Medicina Legal, ajudou a fundar, juntamente com Juliano Moreira e Alfredo Britto, a Sociedade de Medicina Legal da Bahia, sendo eleito presidente. Ainda neste ano foi aceito como membro da Médico-Legal Society de Nova Iorque (Corrêa, 2001; Oda, 2003).

Nos primeiros anos da década de 1900, Nina Rodrigues se dedicou a uma série de escritos sobre Medicina Legal voltados à perícia médica, e outros de especial interesse para a psicologia, tais como "Atavisme psychique et paranóia", publicado nos Archives de Anthropologie Criminel de Lion em 1902 e "La paranóia chez les nègres", do ano seguinte, publicado na mesma revista. Raimundo Nina Rodrigues faleceu precocemente em julho de 1906, deixando uma obra de importância ímpar para os estudos sobre raça no Brasil.

De acordo com Ana Maria Oda (2003), pode-se classificar a produção de Nina Rodrigues em quatro pontos, são eles: os estudos de organização sanitária pública; medicina legal, psiquiatria forense e antropologia física; os estudos de psicopatologia comparada e, finalmente, a etnografia dos povos africanos da Bahia. Exceto o primeiro item, que apresenta um limite temporal específico - o início da carreira de Nina Rodrigues -, todos os outros temas estão presentes ao longo dos seus vinte anos de produção, sendo que o tema da criminalidade entre negros e mestiços perpassa boa parte de sua obra.

A atuação de Nina Rodrigues dentro da Medicina Legal foi muito ampla, podendo ser localizada em diversos âmbitos que vão desde a organização sanitária até a psiquiatria forense. Aqui interessam, principalmente, seus trabalhos sobre antropologia física e criminal e psiquiatria forense, dentro dos quais o estudo do corpo e da mente 
do negro se sobrepõe. Voltado principalmente ao tema da criminalidade racial, Nina Rodrigues analisou diversos casos de delitos envolvendo negros e mestiços, nos quais os corpos, cabeças, mentes e história de vida dos sujeitos eram avaliados no intuito de desvendar as motivações de seus crimes.

\section{Raça, crime e punição}

A conversão absoluta de Nina Rodrigues ao campo da Medicina Legal pode ser datada na publicação de "As Raças Humanas e a Responsabilidade Penal no Brasil", de 1894. O livro é dedicado aos consagrados médicos e juristas da área, como Lombroso, Ferri, Garófalo e Lacassagne 2, "em homenagem aos relevantes serviços que os seus trabalhos estão destinados a prestar a medicina legal brasileira, atualmente simples aspiração ainda" (Rodrigues, 1957, p.21). De acordo com Maio (1995), além disso, percebe-se também uma identificação do autor com as teorias eugênicas de Galton e com o darwinismo social de Spencer.

Mas, foi principalmente baseado nas teorias lombrosianas que Nina Rodrigues desenvolveu as ideias apresentadas em "As Raças Humanas", no qual o autor considerava um "simples ensaio de psicologia criminal brasileira" (Rodrigues, 1957, p.24). Fundamentado, sobretudo, nas aulas que vinha ministrando na disciplina de Medicina Legal da Faculdade de Medicina da Bahia, o livro tinha como propósito apresentar as modificações que as condições de raça imprimiriam à responsabilidade penal, assim como criticar o Código Penal Brasileiro de 1890.

Neste livro, considerado por Leite (1992) a exposição explícita de preconceito contra índios e negros, Nina Rodrigues defendeu um tratamento diferenciado para negros, índios e mestiços - produtos das chamadas raças inferiores - no Código Penal Brasileiro. Seu argumento partia do pressuposto de que haveria uma diferença fundamental entre as raças no que se referia à sua constituição mental:

A concepção espiritualista de uma alma da mesma natureza em todos os povos, tendo como conseqüência uma inteligência da mesma capacidade em todas as raças, apenas variável no grau de cultura e passível, portanto, de atingir mesmo num representante das raças inferiores, o elevado grau a que chegaram as raças superiores, é uma concepção irremessivelmente condenada em face dos conhecimentos científicos modernos (Rodrigues, 1957, p.28). 
Para embasar sua proposta de um código diferenciado, Nina Rodrigues utilizou longas citações de autores como Tarde ${ }^{3}$ e Garófalo para sustentar que a própria noção de crime se altera conforme o tempo e a sociedade. Assim, lembra que o grande crime na Grécia Antiga era deixar os pais sem sepultura, na Idade Média era o sacrilégio, tendo o homicídio pena muito mais leve. Se a ideia de crime se alterou ao longo do tempo, nada mais natural que a ideia de justiça se modificasse também. Para que todos tivessem a mesma noção de justiça e responsabilidade, era necessário, segundo o autor, que houvesse uma homogeneidade populacional, o que era impensável, uma vez que as populações se encontravam em níveis distintos de evolução mental. Assim, Nina Rodrigues concordou com Tarde quando este afirmou que para se chegar a homogeneidade populacional era preciso que:

As inclinações naturais, quaisquer que sejam, tenham recebido, em larga escala, do exemplo ambiente, da educação comum, do costume reinante, uma direção particular que as tenha especificado [...]. Quando a sociedade tem fundido assim à sua imagem todas as funções e todas as tendências orgânicas do indivíduo, o indivíduo não faz um movimento, um gesto, que não seja orientado para um fim designado pela sociedade. Além disso, é preciso que, em larga escala também, as sensações brutas fornecidas pelo corpo e a natureza exterior em face um do outro, tenham sido profundamente elaboradas pelas convenções, pela instrução, pela tradição, e convertidas deste modo em um conjunto de ideias precisas, de juízos e de prejuízos, conformes em maioria às crenças dos outros, ao gênio da língua, ao espírito da religião ou da filosofia dominante, à autoridade dos avós ou dos grandes contemporâneos. Depois disso, pense o que pensar o indivíduo, ele há de pensar com o cérebro social" (Tarde apud Rodrigues, 1957, p.45).

Uma vez que a cada fase da evolução social de um povo corresponderia um tipo específico de criminalidade (de acordo com o desenvolvimento intelectual e moral) e que a análise científica mostrava a impossibilidade de uma homogeneidade populacional, o pressuposto da vontade livre, ou livre arbítrio - doutrina que estaria, segundo Oda (2003), de acordo com a Escola Clássica de Direito, na qual se baseava o sistema penal brasileiro à época - , não ofereceria a mínima consistência porque não escaparia, segundo Nina Rodrigues, às contingências do desenvolvimento evolutivo. Seguindo a teoria spenceriana ${ }^{4}$, o autor acreditava que toda e qualquer ação seria determinada pelas conexões psíquicas geradas pela experiência - que poderiam ser mesmo anterior à existência do indivíduo - e que 
estavam acumuladas na sua constituição. Assim, o autor concluiu que, a cada fase da evolução da humanidade, se se comparassem raças distintas, corresponderia uma criminalidade própria em harmonia e em acordo com o grau do desenvolvimento. De forma que a noção de vontade só poderia ser aplicada a um grupo social homogêneo, o que não era, nem de longe, o caso da sociedade brasileira.

Aplicando tais conceitos à realidade do Brasil, Nina Rodrigues sustentou que os crimes cometidos por indígenas, negros ou mestiços só poderiam ser analisados a partir de um ponto de vista racial que levasse em conta os valores morais e as noções de justiça vigentes nos seus respectivos grupos, ao que Oda dá o nome de "ética étnica" (2003, p.215). Afirma Nina Rodrigues:

Ora, desde que a consciência do direito e do dever, correlativos de cada civilização, não é o fruto do esforço individual e independente de cada representante seu; desde que eles [índios, negros e mestiços] não são livres de tê-la ou não tê-la assim, pois que essa consciência é, de fato, o produto de uma organização psíquica que se formou lentamente sob a influência dos esforços acumulados e da cultura de muitas gerações; tão absurdo e iníquo, do ponto de vista da vontade livre, é tornar os bárbaros e selvagens responsáveis por não possuir ainda essa consciência, como seria iníquo e pueril punir os menores antes da maturidade mental por já não serem adultos, ou os loucos por não serem sãos de espírito (Rodrigues, 1957, p.79).

Os selvagens - negros e índios - teriam, de acordo com Nina Rodrigues, um código de conduta próprio, estabelecido nos seus locais de origem e que difeririam muito dos códigos de conduta dos povos ditos civilizados.

Os negros africanos são o que são: nem melhores nem piores que os brancos: simplesmente eles pertencem a uma outra fase do desenvolvimento intelectual e moral. Essas populações infantis não puderam chegar a uma mentalidade muito adiantada e para esta lentidão de evolução tem havido causas complexas. Entre essas causas, umas podem ser procuradas na organização mesma das raças negríticas, as outras podem sê-lo na natureza do habitat onde essas raças estão confinadas. Entretanto, o que se pode garantir com experiência adquirida, é que pretender impor a um povo negro a civilização européia é uma pura aberração (Rodrigues, 1957, p.114).

Como exigir, questiona o autor, que todas as diferentes raças encontradas no Brasil respondam por seus atos perante a lei com 
igual plenitude de responsabilidade penal? É possível admitir que os índios e negros, bem como seus mestiços, tenham discernimento para decidir entre cometer ou não um crime? Seria correto, pergunta ainda Nina, conceber que a consciência do dever e do direito destas raças seja a mesma da dos brancos? Nina Rodrigues não pôde responder a estas questões.

Assim, para o autor, um negro que cometesse um crime de honra, por exemplo, não poderia ser julgado da mesma maneira que um branco que tivesse cometido o mesmo crime. Suas aptidões mentais, suas formas de ver o crime e seus códigos de conduta eram outros. 0 branco deveria ser punido mais severamente que o negro, pois ele teria domínio sobre o código da civilização. Sua superioridade mental o obrigaria a ter consciência e pensar racionalmente sobre o crime que porventura viesse a cometer, diferentemente do negro, que seria acometido por suas emoções, que dominariam sua consciência, incapacitando-o para a racionalidade. $\mathrm{O}$ caso do indígena (puro) era o mesmo que o do negro.

Basta refletir um instante em que só os africanos e os índios conservam, mais ou menos alterados, do novo meio social, os seus usos e costumes, como ainda em que fazem deles com os novos um amalgama indissolúvel, para se prever que nas suas ações hão de influir poderosamente as reminiscências, conscientes ou inconscientes da vida selvagem de ontem, muito mal contrabalançadas ainda pelas novas aquisições emocionais da civilização que Ihes foi imposta (Rodrigues, 1957, p.79).

Desta forma, não havia duvidas de que negros e índios necessitavam de um código que previsse sua incapacidade e atenuasse sua responsabilidade. No caso dos mestiços, a situação se complicaria mais.

Para Nina Rodrigues, a escala da mestiçagem poderia ir desde o "produto inteiramente inaproveitável e degenerado ao produto válido e capaz de superior manifestação da atividade mental" (Rodrigues, 1957, p.134). A mesma escala deveria percorrer a responsabilidade moral e penal, uma vez que o autor não considerava que todos fossem irresponsáveis. Nina Rodrigues acreditava que os mestiços poderiam ser distribuídos em três grupos distintos: o primeiro corresponderia aos mestiços superiores que, ou pela predominância da raça civilizada em sua constituição, ou por uma feliz combinação mental, poderiam ser considerados perfeitamente equilibrados e plenamente responsáveis; ao segundo grupo pertenciam os mestiços evidentemente degenerados, os quais devem ser considerados parcial ou totalmente irresponsáveis; por fim, no último grupo estariam os mestiços comuns, que mesmo superiores às raças selvagens das quais descendiam, traziam o desequilíbrio causado pelo cruzamento, 
não podendo ser equiparados àquelas raças, de forma que se encontravam em constante iminência de cometer ações anti-sociais e não deveriam, por isso, ser plenamente responsáveis.

A sugestão proposta por Nina Rodrigues foi de que cada região do país possuísse seu próprio código, adaptado às condições raciais e climáticas de cada uma delas, abandonando a unidade legal que era defendida pelo direito clássico. Mas, como bem lembra Oda, é claro que a distinção no código proposta pelo autor implicaria não apenas na imputabilidade penal, mas, também, na "relativização da capacidade civil, isto é, da cidadania no sentido amplo" (2003, p.217).

Após "As Raças Humanas", Nina Rodrigues passou a escrever frequentemente sobre a relação entre raça e crime. Nesses textos, sempre defendeu a responsabilidade diferenciada como a melhor forma de tratar os casos criminais, para comprovar suas teorias, utilizava-se, sobretudo, de observações empíricas. Encontram-se exemplos desse método em textos como "Depeçage Criminel", "Lucas da Feira", aqueles sobre o conflito de Canudos, como "Antônio Conselheiro e os Jagunços", entre outros.

\section{0 caso de Lucas da feira}

Seguindo o método de Nina, vamos aqui nos detalhar na apresentação de seu ensaio sobre Lucas da Feira, publicado em 1985. É comum que, à primeira leitura deste texto, não Ihe seja dada muita relevância: parece ser apenas mais um dos textos racistas de Nina Rodrigues, no qual o corpo do negro fora medido, analisado e profanado. Uma segunda leitura, mais aprofundada, nos mostra que o texto ultrapassa esta primeira visão e pode ser localizado entre as obras chave do que, penso, ser a transição de um Nina Rodrigues simplesmente cientificista e médico para um Nina Rodrigues afetado pela importância dos indicadores sociais.

Adepto da teoria lombrosiana do criminoso nato, logo no início o autor afirma crer que "poucas populações estarão, como a do Brasil, em condições de oferecer à escola criminalística italiana uma confirmação mais brilhante às doutrinas que ela defende" (Rodrigues, 2006, p.104). Ironicamente, ao longo do texto percebe-se que ele mais se afastou do que aproximou das doutrinas que tanto elogiava. Vejamos o caso de Lucas.

Lucas da Feira foi um negro escravo fugido que, em 1828, juntou um bando de negros - escravos como ele - cometendo diversos crimes ao longo de vinte anos. Em 1848, Lucas foi preso, negando seus crimes de início, mas, após intenso interrogatório, acabou por admitir ter matado mais de vinte pessoas, roubado e raptado, além de ter violado seis moças (Rodrigues, 2006). Ainda assim, e mesmo 
sabendo que seus dias estavam contados, afirmou que não entregaria nenhum de seus comparsas por ser este um ato de traição para com aqueles que tanto o ajudaram. Não era este o comportamento previsto por Lombroso para os criminosos: estes sempre buscariam atenuar seus atos acusando outros e reclamando terem cometido seus crimes sob influência e domínio dos cúmplices. Contudo, não foi somente o comportamento de Lucas depois de preso que não estava de acordo com a teoria italiana; seu comportamento durante a vida e seu corpo após a morte não se pareciam em quase nada com a descrição do criminoso nato.

Durante a vida de crimes, Lucas evitou, sempre que pôde, assaltar e assassinar pessoas da vila, porque os conhecia: "Assim, pois, como verdadeiro selvagem, a vila e seus habitantes representavam para ele sua pátria, sua tribo, seu clã: os outros não eram mais do que estrangeiros em face dos quais ele não se julgava obrigado a ter considerações" (Rodrigues, 2006, p.108).

Este comportamento de Lucas - que, mesmo fugindo, também respeitou seus senhores e nunca os machucou, além de só ter matado quem ele entendia tê-lo traído de alguma forma, certo que com requintes de grande crueldade - demonstrava para Nina Rodrigues que Lucas era sim um verdadeiro criminoso, porque tinha instintos sanguinários, mas não era um criminoso nato.

Por fim, o estudo de seu crânio demonstrou que, ao contrário do que o médico esperava, Lucas da Feira não possuía nenhum traço étnico marcante; à primeira vista parecia um crânio perfeitamente normal, com caracteres próprios aos crânios dos negros, mas também àqueles "pertencentes aos crânios superiores, medidas excelentes, iguais às da raça branca" (Rodrigues, 2006, p.106). Lucas era filho de negros africanos e sua negritude era comprovada por todos os que 0 conheceram, de forma que a ideia de que ele tivesse um mínimo de sangue branco era muito pouco provável. As medidas do crânio de Lucas, somadas ao seu comportamento em vida, mostravam a Nina Rodrigues que ele era um criminoso para os brasileiros, que viviam sob civilização europeia, porque provavelmente na África ele teria sido um rei, um guerreiro, um herói.

E assim, Nina Rodrigues chegou à conclusão que o verdadeiro estudo da criminalidade não poderia se firmar somente na craniometria:

Compreende-se assim o valor que se deve dar à ausência de caracteres criminais no crânio de Lucas e vê-se como não podemos criticar os dados da antropologia criminal, prendendonos preconcebidamente aos caracteres físicos com a exclusão de uma sábia análise psicológica. É preciso, antes de tudo, fazer dos criminosos um estudo completo (Rodrigues, 2006, p.164). 
Essa análise completa compreendia, além dos exames osseométricos, um estudo detalhado da vida psicológica da pessoa e o conhecimento do meio social e climático no qual a pessoa vivia, tal como feito pelo autor no ensaio sobre Antônio Conselheiro.

Pode-se analisar o caso de Lucas da Feira por diferentes prismas. Entretanto, para este trabalho, sua relevância encontra-se, sobretudo, no fato de Nina Rodrigues não haver encontrado no corpo de Lucas importantes marcas, traços e características físicas, materiais, de sua degenerescência ou de seu atavismo psíquico. Sim, sabia-se que o ex-escravo era um criminoso, assim como constatavase que era negro. Sabia-se também que era canhoto - marca indiscutível de degenerescência -, que tinha um "olhar peculiar" (Rodrigues, 2006, p.105) e que possuía uma leve anormalidade no formato do crânio. Anomalias estas, aliás, que poderiam também ser encontradas em um indivíduo branco. Ou melhor, que poderiam ser encontradas em qualquer pessoa. Mas Lucas não era qualquer pessoa. Lucas tinha atacado e saqueado diversos vilarejos durante vinte anos. Tinha violado e assassinado, muitas vezes com requintes de crueldades, podendo seus atos serem comparados aos dos assassinos mais bárbaros. Mas, diferentemente dos casos analisados pelo autor em "As Raças Humanas", Lucas possuía um rígido código de conduta: ele só matava quando, em sua avaliação, isto era necessário; não matava conhecidos - mas matava conhecidos traidores, caso em que usava da Lei de Talião além de outros castigos.

Assim, Nina Rodrigues perguntou-se como poderia um negro supostamente degenerado em função de sua raça, cuja mentalidade inferior se comprovaria por seus crimes, possuir um código de conduta tão elaborado? Lucas era, antes de mais nada, um produto de seu meio. Hoje poder-se-ia dizer, inclusive, que Lucas era o que a sociedade e a cultura fizeram dele. Resposta não muito distante da dada pelo médico maranhense em finais do século XIX.

\section{Mestiços e crimes}

Em 1899, Nina Rodrigues escreveu um artigo intitulado "Mestiçagem, Degenerescência e Crime", no qual dava exemplos de crimes cometidos por mestiços. Em sua análise, buscava distinguir a influência da degeneração nos criminosos. Para tanto, contemplou o estudo craniométrico e fisiognômico do criminoso, de acordo com os parâmetros da criminologia. Assim, conduziu a análise dos casos de forma a confirmar sua tese de que os crimes são mais fruto da degenerescência recorrente pelo cruzamento de raças distintas, do que de responsabilidade individual, e por isso deveriam ser atenuados. 
No início deste artigo, Nina Rodrigues discorreu sobre os discursos científicos que, no final do século XIX, debatiam a questão da mestiçagem. Os primeiros referiam-se à discussão entre poligenistas e monogenistas. A visão monogenista congregou a maior parte dos intelectuais que, de acordo com a Bíblia, acreditavam que a humanidade vinha de uma fonte comum, sendo as diferenças entre os homens vistas como um gradiente, que iria do mais ao menos perfeito (mas sem supor uma noção de evolução). Já a visão poligenista provinha de uma interpretação biologicista, baseada na análise dos comportamentos humanos, que passaram a ser crescentemente vistos como resultados imediatos das leis biológicas e naturais e implicando, portanto, diferentes origens humanas (Schwarcz, 1993). Assim, enquanto os primeiros buscavam mostrar o hibridismo dos cruzamentos humanos, os segundos buscavam comprovar a viabilidade de tais cruzamentos. "Assim, o critério de viabilidade e de capacidade dos mestiços foi posto no terreno das ciências naturais. Tanto como para os animais, esse critério deveria ser a perfeita eugenesia dos mestiços humanos, que uns apoiavam e outros negavam" (Rodrigues, 2008, p.1151). No entanto, o debate entre os poligenistas e os monogenistas acabou atenuado com a publicação e divulgação da teoria evolucionista de Darwin, que passou a constituir, segundo Schwarcz (1993), uma espécie de paradigma da época, amenizando antigas disputas.

Deste modo, segundo Nina Rodrigues, a psicologia mórbida entrou em ação e colocou de lado a questão de saber se o mestiço era ou não eugenésico - ou seja, capazes de melhorar a sua descendência , para debater se os mestiços eram um produto normal, socialmente viável ou se, ao contrário, constituiriam "raças abastardas inferiores, uma descendência incapaz e degenerada" (Rodrigues, 2008, p.1152). Neste sentido, a psicologia coletiva - a partir de nomes como Gobineau ${ }^{5}$, Spencer, Keane e Le Bon - ocupou-se da questão. Já o estudo médico da influência degenerativa da mestiçagem era mais recente. Nina Rodrigues lembra que o próprio Morel, "criador da noção clínica de degenerescência" (Rodrigues, 2008, p. 1152) a desconhecia. Foi, portanto, a psicologia criminal que acabou por acentuar, ou afirmar, a possibilidade desta consequência do cruzamento. Mas, ainda assim, poucas ou nulas eram as documentações que apoiassem esta teoria:

A razão principal para essa ausência de documentação é a dificuldade de separar de maneira segura a influência do cruzamento da de muitas outras causas, de ordem biológica e social que pode ter simultaneamente exercido influência na degenerescência ou na decadência precoce desses povos mestiços e que são dadas ou invocadas como provas da ação degenerativa da mestiçagem (Rodrigues, 2008, p. 1152). 
Foi justamente por conta desta ausência de documentação que o autor se propôs a resolver o problema através da observação direta e imediata:

A observação, tal como feita até hoje, voltando-se para todo um povo ou para casos muito limitados e muito específicos, não pode trazer senão provas muito discutíveis e não pode iluminar a questão com as luzes soberanas da verdade. Num país inteiro e sem o recurso a estatísticas no caso dos povos que se prestam a essa discussão, é quase impossível distinguir a influência da mestiçagem entre as mil outras causas complexas, suscetíveis de produzir sua decadência. Em alguns casos muito especiais é sempre justo suspeitar de uma exceção ou de uma influência degenerativa local, responsável pela ação imputável ao cruzamento (Rodrigues, 2008, p.1153).

Assim, Nina Rodrigues afirma que tais análises seriam melhor realizadas em cidades pequenas, "nas quais é mais fácil distinguir as diferentes causas degenerativas, dado que a população local não se distingue em nada do tipo médio geral da província ou estado" (Rodrigues, 2008, p.1153) buscando, também, o histórico médico destas populações. A localidade escolhida, Serrinha - no interior do estado da Bahia -, era composta por mestiços, principalmente pardos, além de possuir uma quantidade significativa de negros. Serrinha também gozava da reputação de abrigar uma população séria e trabalhadora. No entanto, Nina Rodrigues fez questão de mostrar que, apesar da fama, a população local estava longe de ser um exemplo, já que se utilizava de métodos atrasados de produção agrícola, além de não possuir espírito empreendedor, dificultando o progresso da região.

Ao longo do texto, o autor apresentou diversos casos de degenerescência entre a população de Serrinha no intuito de comprovar a sua frequência entre os mestiços, assim como justificar sua tese sobre o fundo degenerativo dos criminosos mestiços:

A degenerescência dos mestiços devia ter uma influência decisiva e predominante sobre sua criminalidade, o que era de prever, mas não seria justo inferir daí que essa criminalidade deva ser forçosamente muito elevada, pois compreendemos perfeitamente que a degenerescência, sob a influência de causas múltiplas e difíceis de precisar, difíceis mesmo de conhecer, pode tomar formas variadas: mais criminosas aqui, mais vesânicas lá, e assim por diante (Rodrigues, 2008, p.1166). 
Vê-se, pois, que Nina Rodrigues acreditava que se a violência e a impulsividade das raças inferiores afetavam a qualidade dos crimes, não necessariamente influenciava na quantidade. O caso de Serrinha era um exemplo de localidade com baixa criminalidade, mas na falta de estatísticas confiáveis, era impossível realizar um estudo comparativo com outras localidades do estado e outras regiões do país, mas, com base em estudos realizados em outros países, o autor acreditava ser possível afirmar que o tipo violento predominava na criminalidade da população de cor. Assim, no intuito de comprovar que a criminalidade é fruto da degenerescência causada pela mestiçagem, o autor acreditou ser suficiente a análise da história de duas famílias, cujos casos de criminalidade associavam-se intimamente com as manifestações da degenerescência, de forma a demonstrar que a tendência ao crime era hereditária.

\section{Desmembramento criminal}

Em 1898, no artigo "Des Conditions Psychologiques du Depeçage Criminel", Nina Rodrigues tratou dos casos de mutilação criminosa. Iniciou o texto citando Lacassagne, que diz que o desmembramento seria um fenômeno presente desde sempre nas culturas primitivas, merecendo, portanto, um estudo mais detalhado, pois seria uma das características mais marcantes do instinto destruidor. Em seus dias, ainda segundo Lacassagne, não havia mais tantos casos como antigamente, não porque os primitivos tivessem aceitado as leis e os costumes da civilização - como pensariam os antropólogos - mas por serem ainda caracterizados por seus instintos atávicos. Assim, para Lacassagne, os primitivos do final do século XIX ainda eram condenados à imitação, tal como seus antecedentes.

Uma vez que o Brasil era, segundo Nina Rodrigues, um país com grande número de pessoas de raças inferiores e, pior, com grande número de produtos do cruzamento entre raças, tinha uma boa parte da população com instintos atávicos e logo o estudo do desmembramento poderia ser muito bem aplicado em nossa terra. Assim, Nina Rodrigues resolveu debruçar-se sob o assunto e estudar o fenômeno do desmembramento no Brasil a partir dos três tipos propostos por Lacassagne - a saber, o desmembramento "religioso" ou "sacrificial"; o "judicial" e o "criminoso", além de um último tipo proposto pelo próprio Nina Rodrigues, o desmembramento "guerreiro" ou "ornamental".

O desmembramento guerreiro - ou de guerra - era comum entre as tribos indígenas que aqui estavam antes da chegada de Portugal. Segundo o autor, era comum que os índios usassem como troféus crânios e membros de seus inimigos, cujos ossos serviam, igualmente, como decoração de corpos e casas. 
Esta prática existe ainda hoje e com a mesma finalidade entre as tribos selvagens que ocupam as extensas zonas desertas do país. Ela existe igualmente entre os descendentes semicivilizados, puros ou mestiços, do índio e do negro, ainda que atenuada, porque transformada em crime, mas o caráter e os instintos guerreiros ainda são facilmente percebidos nestes povos. Nos pontos distantes do litoral, onde pouco se sente a influência da civilização, estes povos nômades vivem em incursões, exatamente como viviam seus antepassados selvagens aqui, na América, ou na África. Estas pessoas estão constantemente envolvidas com assaltos à mão armada onde se revela todos os sentimentos e instintos bárbaros ainda mal contidos de seus ancestrais (Rodrigues, 1898, p.7 [tradução livre]).

A título de exemplo, o autor descreve - com riqueza de detalhes um caso onde um fazendeiro foi morto a tiros por um bando de capangas enquanto dormia, produto de uma vingança dos filhos de um fazendeiro vizinho. Não satisfeitos com o assassinato, o grupo de homens - mestiços - arrastou o corpo até a frente da casa, onde o espancaram e esquartejaram, largando-o no meio do pasto dos animais, ato após o qual atearam fogo nas cabanas dos trabalhadores da fazenda.

A mutilação e a antropofagia religiosa - segundo tipo - também eram comuns entre os índios e entre os negros, tendo sido encontrado não somente na América Central, mas também no Brasil:

Nas minhas pesquisas para um trabalho no qual me ocupo atualmente, sobre a criminalidade entre os negros brasileiros, cheguei a descobrir traços desta abominável prática no Brasil. Pude constatar em uma antiga província do atual Estado do Maranhão, a existência de casos de exumação clandestina de cadáveres de recém-nascidos para a confecção de feitiços (fetiches) ou sortilégios de negras feiticeiras. É quase certo que esta prática tem sido amplamente empregada nos cultos de feitiçaria africana que ainda desfrutam de grande prestígio hoje em dia no Brasil (Rodrigues, 1898, p.7; [tradução livre]).

O terceiro tipo analisado pelo autor é o desmembramento judiciário, feito em nome da lei. O exemplo utilizado pelo autor - o esquartejamento de Tiradentes em 1796 - demonstra bem a importância do ato como, além de punição, exemplo para aqueles que poderiam pensar em se rebelar.

O quarto - e último - tipo analisado foi o criminal, no qual se encontrava o maior interesse do autor. $E$, uma vez que não era fácil 
fazer, através das antigas observações, uma análise sobre o estado mental dos esquartejadores, "porque, (...) mesmo tendo observações deveras interessantes, as doutrinas oficiais - dedicadas ao exame meticuloso dos crimes - mostravam desprezo pelo estudo do criminoso" (Rodrigues, 1898, p.10 [tradução livre]), era importante, portanto, realizar um novo estudo.

O autor descreveu alguns casos de mutilações e passou à análise dos criminosos. No entanto, antes de passar à sua análise é importante abrir um parêntesis: no primeiro caso, um juiz havia esquartejado a amante, ambos brancos. Este, apesar de ser um caso de mutilação, não representava um bom exemplo para o autor, uma vez que o juiz "só" havia esquartejado a amante para que o corpo coubesse na caixa em que seria enterrado, de forma que não houve a intenção do desmembramento. Por coincidência, os casos considerados pelo autor como típicos de desmembramento criminal, foram cometidos por negros/mestiços. E também, por coincidência, são os rostos dos criminosos negros e mestiços que ilustram o artigo.

A seu ver era lamentável que os criminosos não tivessem sido submetidos a exames cuidadosos, porque poderiam seus casos ajudar a melhor compreender o desmembramento criminal. No entanto, o autor pôde perceber que os motivos psicológicos que levariam ao desmembramento de cadáveres seriam múltiplos e variados. A prática obedeceria aos sentimentos mais diversos e conflitantes, não sendo um simples ato, uma vez que seria capaz de influenciar direta e imediatamente a transmissão hereditária ou atávica aos descendentes dos mutiladores.

Nina Rodrigues, assim, considerou que as formas religiosas, guerreiras e judiciárias do desmembramento possuíam uma função social que as explicariam por si mesmas. Era uma prática condenável, sem dúvida, praticada principalmente por povos primitivos, mas que continha na sua função social (e cultural) um atenuante. No entanto, o desmembramento criminal, por sua vez, provinha de um ato criminoso, individual, causado por um retorno atávico. E assim sendo, a degenerescência explicaria - e justificaria - a frequência de criminosos negros e mestiços entre os mutiladores. $E$ o que a degenerescência explicava, a justiça deveria atenuar.

Mas, para Nina Rodrigues, não era somente nos crimes que se percebia o quanto os negros eram degenerados. A degenerescência explicava a alienação entre os negros e mestiços, e que muitas vezes, o crime e a alienação andavam de mãos dadas. De modo que seria difícil dizer, a partir dos casos analisados pelo autor, o que vinha antes: o louco ou o criminoso. A única certeza do autor era a de que os negros e mestiços estavam, por suas condições raciais, mais propensos a uma vida criminosa do que os brancos. 


\section{Considerações finais}

Nos anos que trabalhou no Laboratório de Medicina Legal da Faculdade de Medicina da Bahia, Nina Rodrigues deve ter visto muitos casos de crimes cometidos por negros e mestiços, mais do que por brancos, com certeza. Neste artigo, teve-se por intuito mostrar as formas pelas quais o médico procurou explicar tais índices de criminalidade de acordo com as teorias que estavam em voga na época. Raimundo Nina Rodrigues foi, neste sentido, um intelectual que dialogou com diversos saberes, principalmente europeus, e buscou adaptá-los à realidade brasileira. Pode-se perceber através das suas obras que há um leve progresso, na falta de palavra melhor, que vai de uma dureza teórica baseada na antropologia criminal até um início de uma percepção do relativismo cultural. No entanto, com a precocidade da morte de Nina Rodrigues jamais saberemos que rumo seus estudos teriam tomado no século XX. Hoje, após anos de luta da população negra contra o preconceito racial (luta esta que ainda perdura dia após dia), sabemos que as teorias que Nina Rodrigues tanto acreditava, já não são mais passíveis de serem levadas a sério. No entanto, rever sua obra nos mostra um pouco do quanto os negros foram tratados como objetos pela ciência no Brasil também, e pode deixar a dúvida do quanto tais estudos contribuíram e contribuem para a compreensão da visão que se tem desta parte da população hoje em dia, não só no senso comum, mas pela própria ciência.

\section{Referências}

Corrêa, M. (2001). As Ilusões da Liberdade: a escola Nina Rodrigues e a antropologia no Brasil. Bragança Paulista: Editora da Universidade São Francisco.

Jacó-Vilela, A. M., Espírito Santo, A., \& Pereira, V. (2005). Medicina Legal nas teses da Faculdade de Medicina do Rio de Janeiro (1830-1930): o desencontro entre medicina e direito... Interações , X, 9-34.

Leite, D. M. (1992). O Caráter Nacional Brasileiro. São Paulo: Ática.

Maio, M. C. (1995). A Medicina de Nina Rodrigues: Análise de uma Trajetória Científica. Cadernos de Saúde Pública, 2, 226-237.

Oda, A. M. G. R. (2003) Alienação Mental e Raça: a psicopatologia comparada dos negros e mestiços brasileiros na obra de Nina Rodrigues. Tese de doutorado, Universidade Estadual de Campinas, Faculdade de Ciências Médicas, Campinas, SP. Brasil. 
Readers, G. (1938). D. Pedro II e o Conde de Gobineau (correspondências inéditas). São Paulo: Companhia Editora Nacional.

Rodrigues, R. N. (1898). Des conditions psychologiques du depeçage criminel. Archives d'Anthropologie Criminelle de Criminologie et de Psychologie Normal et Pathologique, 13, pp. 5-33.

Rodrigues, R. N. (1957). As Raças Humanas e a Responsabilidade Penal no Brasil. Salvador: Livraria Progresso.

Rodrigues, R. N. (2006). As Coletividades Anormais. Brasília: Edições do Senado Federal.

Rodrigues, R. N. (2008). Mestiçagem, Degenerescência e Crime. História, Ciência e Saúde - Manguinhos , 15, 1151-1180.

Schwarcz, L. M. (1993). O Espetáculo das Raças. Cientistas, instituições e questão racial no Brasil 1870-1930. São Paulo: Companhia das Letras.

Schwarcz, L. M. (1996). As teorias raciais, uma construção histórica de finais do século XIX: o contexto brasileiro. In: R. Queiroz, \& L. Schwarcz, Raça e Diversidade (pp. 147-185). São Paulo: Edusp.

Ventura, R. (1991). Estilo Tropical: história cultural e polêmicas literárias no Brasil. São Paulo: Companhia das Letras.

\section{Endereço para correspondência \\ Marcela Franzen Rodrigues}

Universidade do Estado do Rio de Janeiro

Programa de Pós Graduação em Psicologia Social

Rua São Francisco Xavier, 524/10ㅇ andar, sala 10.009, bloco F, Maracanã, CEP 20550-013, Rio de Janeiro - RJ, Brasil

Endereço eletrônico: celafranzen@yahoo.com.br e cela.franzen@gmail.com

Recebido em: 30/10/2014

Reformulado em: 14/08/2015

Aceito para publicação em: 19/08/2015

\section{Notas}

* Licenciatura em Ciências Sociais pela Universidade Federal do Rio Grande do Sul - 2002-2007. Mestre em Psicologia Social pela Universidade do Estado do Rio de Janeiro - 2010-2011.Doutoranda em Psicologia Social pela Universidade do Estado do Rio de Janeiro - 2012-corrente.

1 A obtenção do título de doutor era dada ao aluno que, depois de cursada a faculdade de medicina, sustentava em público uma "tese, escrita no idioma nacional ou em latim, e impressa à própria custa. A tese compreendia uma "dissertação" e a enumeração de "proposições" que se traduziam, muitas vezes, na transcrição ipsis verbis de aforismos de Hipócrates" (Jacó-Vilela, Espírito Santo, \& Pereira, 2005, s/p).

2 Cesare Lombroso (1835-1909), Enrico Ferri (1856-1929) e Rafaelle Garófalo (1851-1934) são considerados os fundadores da Escola Italiana de Criminologia, que tinha por objetivo estudar os aspectos físicos, sociais e psíquicos dos criminosos. Alexandre Lacassagne (1843-1924) foi um criminalista francês, ligado à escola lombrosiana. 
3 Jean-Gabriel de Tarde (1843-1904) foi um sociólogo, psicólogo e criminalista francês, famoso pelas suas obras criminais e sobre psicologia das massas.

4 Herbert Spencer (1820-1903) é considerado o criador do darwinismo social. Segundo Ventura, "Spencer defendia a unidade original da espécie humana, e rejeitava a hipótese poligenista sobre a diversidade das raças primitivas. Para ele, as raças se encontravam em estágios evolutivos distintos, sendo as diferenças entre os povos o resultado do progresso de alguns grupos e do atraso de outros. Pela 'lei da repetição abreviada da história', todos os povos passariam pelos mesmos estádios evolutivos" (Ventura, 1991, p. 51[grifos e aspas no original]).

5 As teorias racistas de Arthur de Gobineau foram muito difundidas no Brasil, principalmente por sua relação próxima com Dom Pedro II, fortificada após o ano de 1869, quando o então Conde de Gobineau foi Ministro da França no Brasil (Readers, 1938). O francês havia escrito, em 1854, o livro Essai sur l'inegalité dês races humaines, no qual profetizava a decadência da civilização como resultado da mistura de sangues Acreditava que "a miscigenação estaria colocando em risco as nacionalidades pela introdução de elementos 'heterogêneos', capazes de destruir a sua identidade" (Ventura, 1991). Sobre Gobineau, ainda vale a pena citar a descrição de Schwarcz (1996): "Gobineau esteve no Brasil como enviado francês, odiou tudo o que viu e disse que todos os brasileiros se pareciam com macacos, menos D. Pedro II, que por sua vez tinha muitas espinhas" (p.171). Nina Rodrigues fazia frequentes referências ao trabalho de Gobineau ao longo de seus textos. 